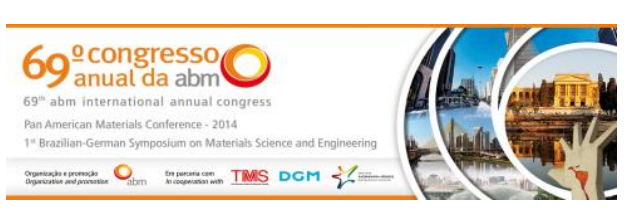

Tema: Lavra e Tratamento de Minérios

\title{
CARACTERÍSTICAS DE QUEBRA DE UM FLOGOPITITO PARA USO EM ROCHAGEM*
}

\author{
Claudio L. Schneider ${ }^{1}$ \\ Thaís Ferreira Marks Brasil Duque ${ }^{2}$ \\ Isabella Cesario de Amaral Souza ${ }^{3}$ \\ Marisa Bezerra de Mello Monte ${ }^{4}$
}

\section{Resumo}

Um flogopitito originário de um garimpo de exploração de esmeralda, na Bahia, está sendo estudado para utilização como fonte de potássio em técnicas de rochagem. Para este fim, é necessário cominuir a rocha até um tamanho apropriado. Estudos de cinética de dessorção e casa de vegetação estão sendo realizados com a finalidade de determinar o tamanho ideal de partícula para aplicações práticas. 0 custo associado à cominuição da rocha é um fator determinante na viabilidade econômica do uso da rocha como insumo na agricultura. Sendo assim, um programa de caracterização completo foi realizado para determinar rotas de britagem e moagem econômicas para esta rocha. Os resultados são apresentados de forma aplicada, com exemplos de circuitos e demanda energética.

Palavras-chave: Rochagem; Cominuição; Energia; Flogopitito.

\section{BREAKAGE CHARACTERISTICS OF A PHLOGOPITITE FOR USE AS STONEMEAL}

\section{Abstract}

A phlogopitite originated from an emerald mining exploration, in Bahia, is being studied for use as a source of potassium in stonemeal techniques. To this end, it is necessary to comminute the rock until an appropriate size. Kinetic studies of desorption and greenhouse are being conducted in order to determine the optimum particle size for practical applications. The cost associated with the comminution of the rock is a determining factor in the economic viability of using the rock as an input in agriculture. Therefore, a complete characterization program was conducted to determine economic routes for crushing and grinding this rock. The results are presented in the applied form, with examples of circuits and energy demand.

Keywords: Stonemeal; Comminution; Energy; Phlogopitite.

1 Engenheiro de Minas, PhD., Tecnologista Sênior, Coordenação de Processos Minerais, Centro de Tecnologia Mineral, Rio de Janeiro, Rio de Janeiro, Brasil.

2 Engenheira Química, M.Sc. (em andamento), Colaboradora, Coordenação de Processos Minerais, Centro de Tecnologia Mineral, Rio de Janeiro, Rio de Janeiro, Brasil.

3 Química, M.Sc., Bolsista de Programa de Capacitação Institucional do CNPq, Coordenação de Processos Minerais, Centro de Tecnologia Mineral, Rio de Janeiro, Rio de Janeiro, Brasil.

4 Engenheira Química, D.Sc., Tecnologista Pleno, Coordenação de Planejamento, Gestão e Inovação, Centro de Tecnologia Mineral, Rio de Janeiro, Rio de Janeiro, Brasil.

\footnotetext{
* Contribuição técnica ao 69ำ Congresso Anual da ABM - Internacional e ao 14ํㅡㄹ ENEMET - Encontro Nacional de Estudantes de Engenharia Metalúrgica, de Materiais e de Minas, 21 a 25 de julho de 2014, São Paulo, SP, Brasil.
} 


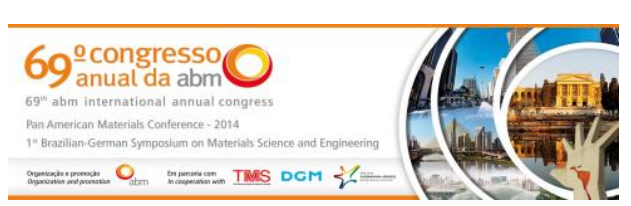

\section{INTRODUÇÃO}

Técnicas de rochagem têm sido escrutinadas em função de vários resultados positivos relatados na literatura e também em função da dependência do Brasil em fontes externas de potássio como fertilizante. Algumas questões chave devem ser abordadas como, por exemplo, determinar se partículas de rocha no solo liberam nutrientes. Outra questão importante é quanto ao tamanho destas partículas e, consequentemente, a demanda energética de britagem/moagem da rocha. Em função disso, um projeto abrangente foi contemplado ao CETEM com recursos do fundo CT-Mineral do CNPq, em parceria com a Embrapa Solos.

A rocha escolhida é o flogopitito, principalmente composta de mica flogopita que, por sua vez, é um filosilicato rico em potássio. As biotitas e flogopitas são importantes micas trioctaédricas. As biotitas apresentam composições variadas, como pode ser observado na Figura 1. A flogopita $\left(\mathrm{K}_{2} \mathrm{Mg}_{6}\left[\mathrm{Si}_{6} \mathrm{Al}_{2} \mathrm{O}_{20}\right](\mathrm{OH})_{4}\right)$ é aquela com maior teor de magnésio em sua composição, por sua vez, a annita $\left(\mathrm{K}_{2} \mathrm{Fe}_{6}\left[\mathrm{Si}_{6} \mathrm{Al}_{2} \mathrm{O}_{20}\right](\mathrm{OH})_{4}\right)$ tem maior teor de ferro. Nem a flogopita nem a annita tem o íon Al em sítios $Y$, mas, na maioria das biotitas naturais, existe uma substituição apreciável do íon Al pelos íons $\mathrm{Mg}$ ou Fe balanceado pela substituição do íon Al pelo íon Si em locais tetraédricos (esse fenômeno é chamado de substituição de Tschermak). Se a molécula for rica em ferro, conduzirá para a siderofilita $\left(\mathrm{K}_{2} \mathrm{Fe}_{4} \mathrm{Al}_{2}\left[\mathrm{Si}_{4} \mathrm{Al}_{4} \mathrm{O}_{20}\right](\mathrm{OH})_{4}\right)$ e se for rica em magnésio conduzirá para a molécula sem nome definido $\mathrm{K}_{2} \mathrm{Mg}_{4} \mathrm{Al}_{2}\left[\mathrm{Si}_{4} \mathrm{Al}_{4} \mathrm{O}_{20}\right](\mathrm{OH})_{4}$. Essa molécula foi, em uma determinada época conhecida como eastonita, mas o nome foi abandonado. Como pode ser visto, não há uma demarcação certa entre flogopitas e biotitas [1].

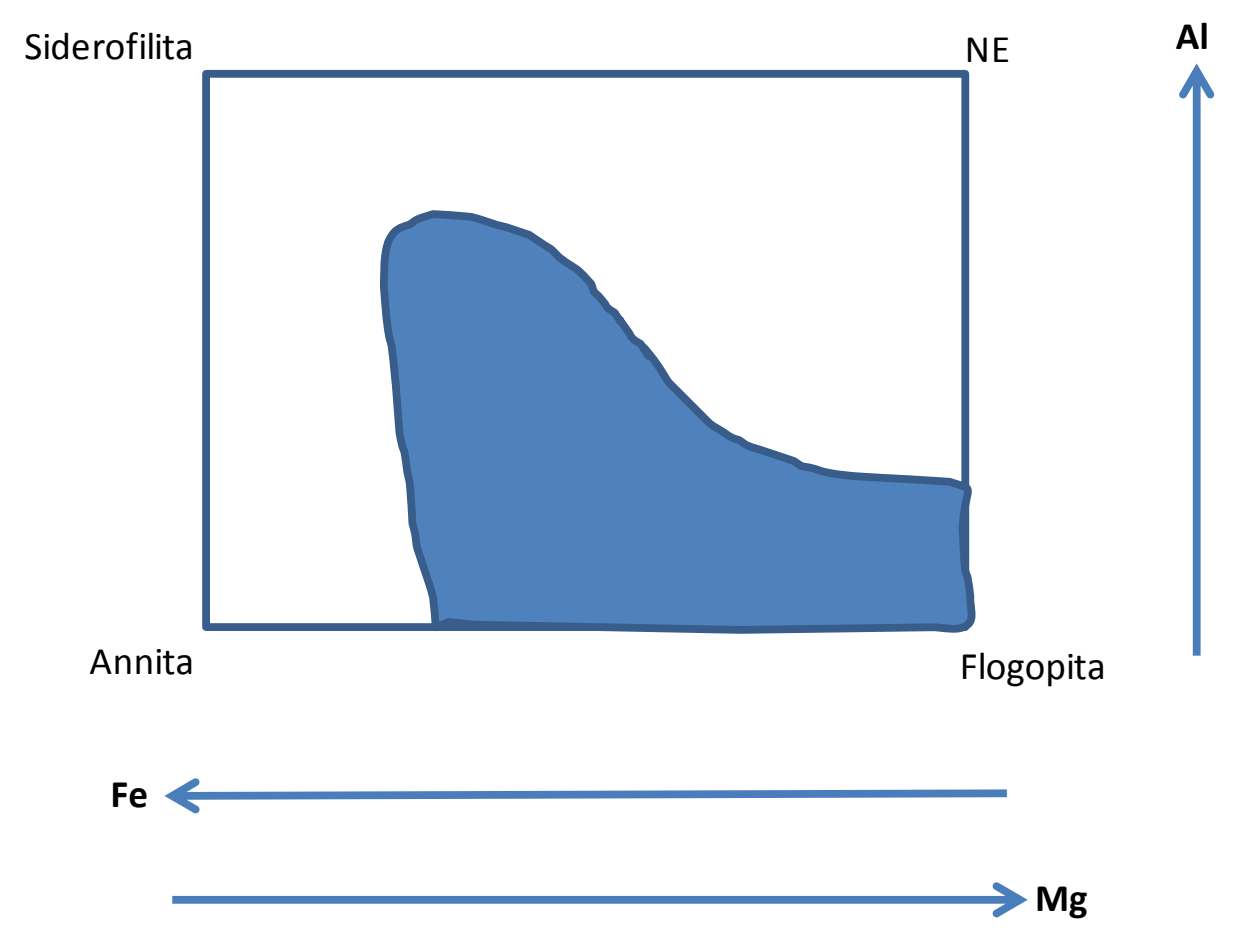

Figura 1. Os principais componentes das composições das biotitas e o campo em que a maioria das biotitas naturais ocorre.

\footnotetext{
* Contribuição técnica ao $69^{\circ}$ Congresso Anual da ABM - Internacional e ao 14ํㅡㄹ ENEMET - Encontro Nacional de Estudantes de Engenharia Metalúrgica, de Materiais e de Minas, 21 a 25 de julho de 2014, São Paulo, SP, Brasil.
} 


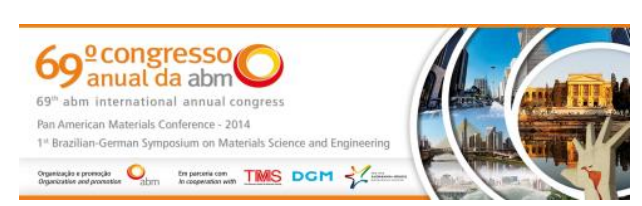

A rocha flogopitito foi utilizada nesse estudo por possuir em sua composição uma grande quantidade do mineral flogopita, cujas concentrações de potássio podem ser expressivas, de até aproximadamente 10\% [2].

Estudos de rochagem em geral envolvem amostras de rocha cominuída. Anterior a este trabalho, não existem informações que relacionam claramente a liberação do potássio (ou outro íon de interesse) com a granulação do material utilizado. Esperase que com granulação mais fina, a liberação de potássio seja maior, porém a produção de partículas finas demanda energia, e inevitavelmente, quanto mais fina a granulação maior a demanda energética.

A cominuição do flogopitito envolve necessariamente etapas de britagem e, para a produção de material fino, moagem. Desta forma, a amostra foi caracterizada quanto à moagem utilizando-se diversos métodos de caracterização, DWT e CWI para a britagem e BWI e Herbst-Fuerstenau para a moagem. Adicionalmente, o índice de abrasividade da rocha foi medido com o objetivo de estabelecer o consumo de aço nas etapas de cominuição. A rocha também foi caracterizada quanto às suas propriedades na prensa de rolos de alta pressão (HPGR).

\section{MATERIAIS E MÉTODOS}

\subsection{Ensaio DWT}

A amostra de flogopitito disponível não continha partículas grosseiras suficientes para realizar o ensaio de DWT completo. Assim, foram selecionadas 150 partículas na faixa de $22,4 \times 19 \mathrm{~mm}$ para um ensaio de DWT simplificado. Nesta versão do DWT simplificado, cinco energias específicas de impacto foram testadas, nominalmente $2,5,2,0,1,5,1,0$ e $0,5 \mathrm{kWh} / \mathrm{t}$, cada energia com 30 partículas na faixa de tamanho especificada. O ensaio foi realizado no JKTech DWT do CETEM. O DWT fornecido pelo JKTech tem acionamento pneumático de todas as funções e pode operar com alturas de até $100 \mathrm{~cm}$ e pesos de até $50 \mathrm{~kg}$.

\subsection{Ensaio de $A \boldsymbol{I}$}

O índice de abrasividade de Bond foi medido para a amostra de flogopitito utilizando o equipamento específico para este ensaio. O teste padrão de abrasividade, desenvolvido pela Allis-Chalmers, é feito em um tambor rotativo com uma palheta de aço SAE 4340 de dimensões padronizadas, montada no eixo central do tambor. A palheta gira na mesma direção do tambor, porém, com uma velocidade aproximadamente nove vezes maior. A amostra é dividida em quatro lotes de $400 \mathrm{~g}$ de partículas entre 19 e $12 \mathrm{~mm}$ e a palheta é limpa e pesada. Cada lote é processado durante 15 minutos, separadamente. Ao final do ensaio a palheta é retirada e limpa. A diferença de peso entre o peso inicial e final da palheta, em gramas, é o valor do Al.

\subsection{Ensaio de Moagem BWI}

O ensaio é um teste de moabilidade em circuito fechado feito em um moinho de bolas padronizado. O teste é feito em circuito fechado com uma peneira (malha de teste). A abertura da peneira pode ter qualquer valor entre $2,83 \mathrm{~mm}$ (7\#) e 45 micrômetros (325\#), contanto que a amostra contenha algum material retido na

\footnotetext{
* Contribuição técnica ao $69^{\circ}$ Congresso Anual da ABM - Internacional e ao 14ํㅡㄹ ENEMET - Encontro Nacional de Estudantes de Engenharia Metalúrgica, de Materiais e de Minas, 21 a 25 de julho de 2014, São Paulo, SP, Brasil.
} 


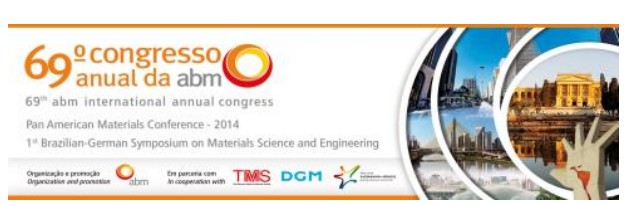

peneira de teste. A malha de teste padrão é a de $150 \mu \mathrm{m}$ (100\#). O ensaio requer $10 \mathrm{~kg}$ de amostra britada em $100 \%$ menor que $3,36 \mathrm{~mm}(6 \#)$. O ensaio é realizado segundo a Norma ABNT MB-3253 de Setembro de 1990 registrada no INMETRO como NBR 11376.

\subsection{Ensaio de Moagem Herbst-Fuerstenau $(H-F)$}

O ensaio de moagem $H-F$ é realizado em um moinho de bolas de laboratório com uma carga de bolas de equilíbrio. A carga de equilíbrio é calculada considerando-se uma distrbuição de diâmetros de Gaudin-Shuhmann com inclinação igual a 4, truncada em um diâmetro de bolas igual a um décimo do diâmetro do moinho. Em geral, quatro tamanhos de bolas distintos são suficientes para emular uma carga de equilíbrio, com bolas de aço padrão. O ensaio é realizado em um moinho com oito levantadores de carga distribuídos de forma simétrica. As condições de moagem são similares às condições em um moinho industrial. $O$ equipamento do CETEM inclui um medidor de potência, necessário para o cálculo da taxa de quebra específica em energia. Os ensaios são realizados a seco e com água, objetivando um produto na especificação da moagem industrial $(P 80)$ e os tempos de moagem são calculados de acordo com esta especificação. Os parâmetros de balanço populacional são calculados utilizando-se um software especializado (BatchMill ${ }^{\mathrm{TM}}$ ). Os parâmetros servem para simulação e escalonamento de moinhos tubulares convencionais e de moinhos verticais (Vertimil/ ${ }^{\mathrm{TM}}$ ).

\subsection{Ensaio na Prensa de Rolos de Alta Pressão (HPGR)}

Amostras pesando $5 \mathrm{~kg}$ e bitoladas em $10 \mathrm{~mm}$ foram testadas na prensa $L A B W A L$ do CETEM utilizando-se pressões hidráulicas iniciais de 10, 20, 30, 40, 50 e 60 bar. Um sistema de aquisição de dados foi utilizado para determinar a potência de moagem, pressão (e força) de moagem assim como o vão entre os rolos, além de medir a capacidade. A distribuição granulométrica dos produtos foi determinada após banho ultrassônico de 15 minutos. Parâmetros de balanço populacional para simulação e escalonamento foram determinados a partir dos resultados utilizando-se um software especializado, desenvolvido especificamente para este fim [3].

\section{RESULTADOS E DISCUSSÃO}

\subsection{Resultados do Ensaio DWT simplificado}

O ensaio de DWT simplificado resultou nos valores mostrados na Tabela1:

Tabela 1. Parâmetros derivados do Ensaio DWT

\begin{tabular}{cc}
\hline $\mathrm{A}, \%$ & 52,77 \\
\hline $\mathrm{b}, \mathrm{t} / \mathrm{kWh}$ & 1,41 \\
\hline $\mathrm{Axb}$ & 74,61 \\
\hline$c$ & 0,59 \\
\hline$C W l, k W h / t$ & 8,95 \\
\hline
\end{tabular}

O produto dos valores $A$ e $b$ tem sido utilizado como um indicador qualitativo da tenacidade do material caracterizado. Esta classificação é mostrada na Tabela 2.

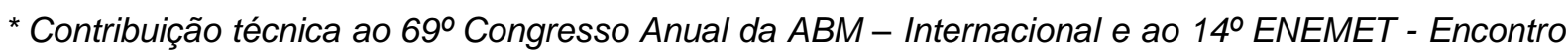
Nacional de Estudantes de Engenharia Metalúrgica, de Materiais e de Minas, 21 a 25 de julho de 2014, São Paulo, SP, Brasil.
} 


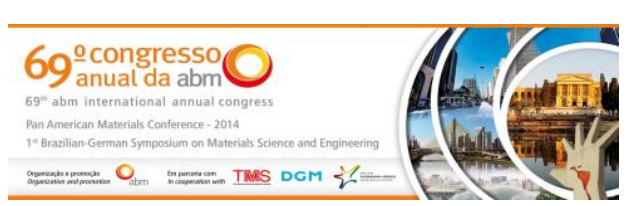

Tabela 2. Classificação qualitativa de tenacidade

\begin{tabular}{|c|c|c|c|c|c|c|c|}
\hline Propriedade & $\begin{array}{l}\text { Muito } \\
\text { Tenaz }\end{array}$ & Tenaz & $\begin{array}{c}\text { Moderadamente } \\
\text { Tenaz }\end{array}$ & Médio & $\begin{array}{l}\text { Moderadamente } \\
\text { Friável }\end{array}$ & Friável & $\begin{array}{l}\text { Muito } \\
\text { Friável }\end{array}$ \\
\hline$A \times b$ & $<30$ & $30-38$ & $38-43$ & $43-56$ & $56-67$ & $67-127$ & $>127$ \\
\hline
\end{tabular}

Portanto, o flogopitito deste trabalho é uma rocha friável, e que demanda pouca energia nas etapas de britagem. $O$ valor do produto $A \times b$ também pode ser utilizado no cálculo do CWI (Crusher Work Index), que é um parâmetro que permite estimar a demanda energética de operações de britagem. A correlação entre o $A \times b$ e o CWI é mostrada na Eq. (1) [4]:

$$
C W I=\exp \left(\frac{\operatorname{Ln}\left(\frac{1842}{A \times b}\right)}{1,463}\right)=8,95 \mathrm{kWh} / \mathrm{t}
$$

\subsection{Resultados do Ensaio de AI}

O índice de abrasividade de Bond foi medido utilizando-se a metodologia padrão do ensaio. $O$ resultado obtido foi $A l=0,008 \mathrm{~g}$. Este valor indica um material muito pouco abrasivo. Para fins de comparação, o $A l$ do flogopitito é comparado com o $A l$ medido em outras rochas [5] na Figura 2.

Este resultado demonstra claramente que o flogopitito é um material não abrasivo e consequentemente, os custos operacionais que resultam do desgaste de revestimentos de moinhos e britadores e do desgaste de corpos moedores serão negligíveis. Consequentemente, os custos de cominuição do flogopitito podem ser considerados somente do ponto de vista energético.

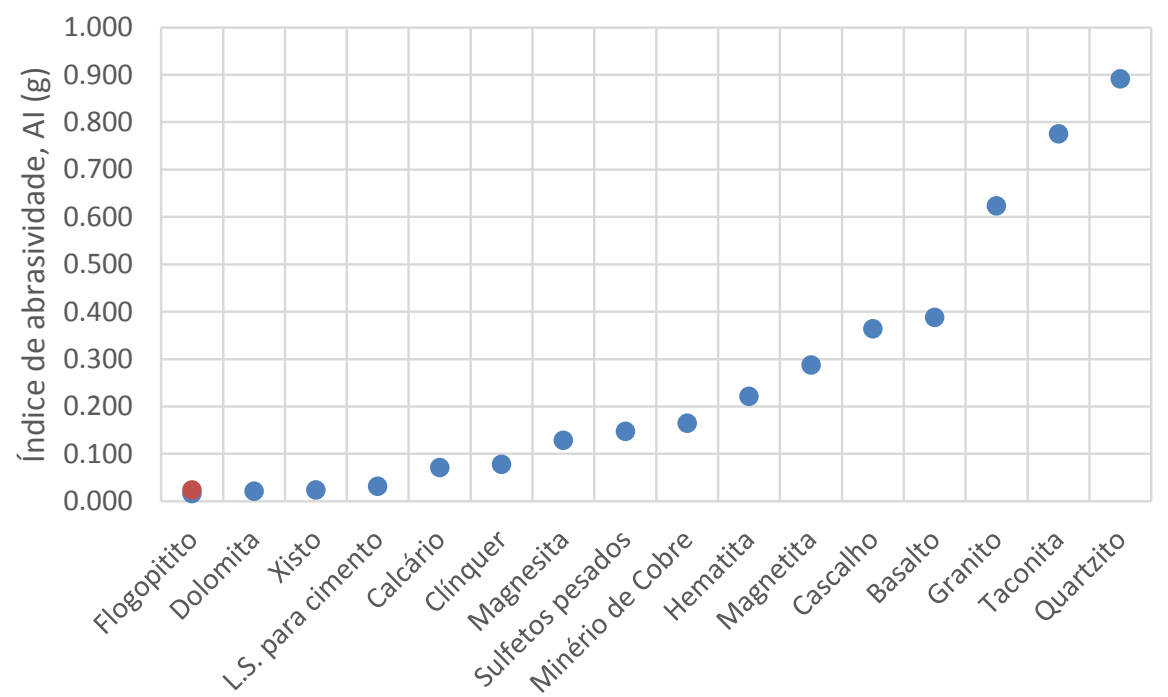

Figura 2. Índice de abrasividade, $A l$, de diversos insumos minerais, em comparação com $\circ A l$ do flogopitito deste trabalho.

\subsection{Resultados do Ensaio de Moagem BWI}

O ensaio de moagem padrão de Bond para determinação do $B W I$ produziu um resultado interessante. Inicialmente não houve convergência para a malha de teste de $150 \mu \mathrm{m}$. Assim, foram testadas as malhas de $212 \mu \mathrm{m}, 250 \mu \mathrm{m}$ e $300 \mu \mathrm{m}$, sucessivamente, obtendo-se convergência somente na malha de $300 \mu \mathrm{m}$. Este

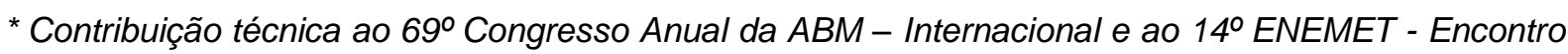
Nacional de Estudantes de Engenharia Metalúrgica, de Materiais e de Minas, 21 a 25 de julho de 2014, São Paulo, SP, Brasil. 


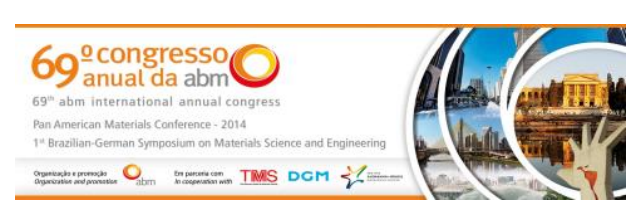

comportamento pode ser explicado pelo fato da mica flogopita, principal constituinte do flogopitito, ser um filosilicato flexível. Quando a redução de tamanho é tal que as partículas se resumem a cristais individuais, as folhas, do tamanho da sessão basal, dobram quando submetidas ao impacto, e não fragmentam. Para chegar a $80 \%$ passante na malha de teste, pelo menos $80 \%$ dos cristais de flogopita devem ter sessão basal menor que a malha de teste. Esta condição existe a partir de $300 \mu \mathrm{m}$ ou tamanhos maiores. Para malhas de teste menores que $300 \mu \mathrm{m}$, o BWI é infinito.

$O$ resultado do ensaio para a malha de $300 \mu \mathrm{m}$ mostra um $B W I$ muito alto, da ordem de $44 \mathrm{kWh} / \mathrm{t}$. Este valor contrasta com o CWI baixo $(\sim 9 \mathrm{kWh} / \mathrm{t})$ e a alta friabilidade do flogopitito quanto à britagem. Isso caracteriza uma descontinuidade de comportamento, que pode ser explicada pela distribuição de tamanhos das sessões basais dos cristais individuais. O P80 produzido no ensaio foi de $228 \mu \mathrm{m}$.

Algumas imagens de partículas de flogopitito foram obtidas com o auxílio de uma lupa para verificar o tamanho aproximado das sessões basais da flogopita. Duas imagens são mostradas na Figura 3.
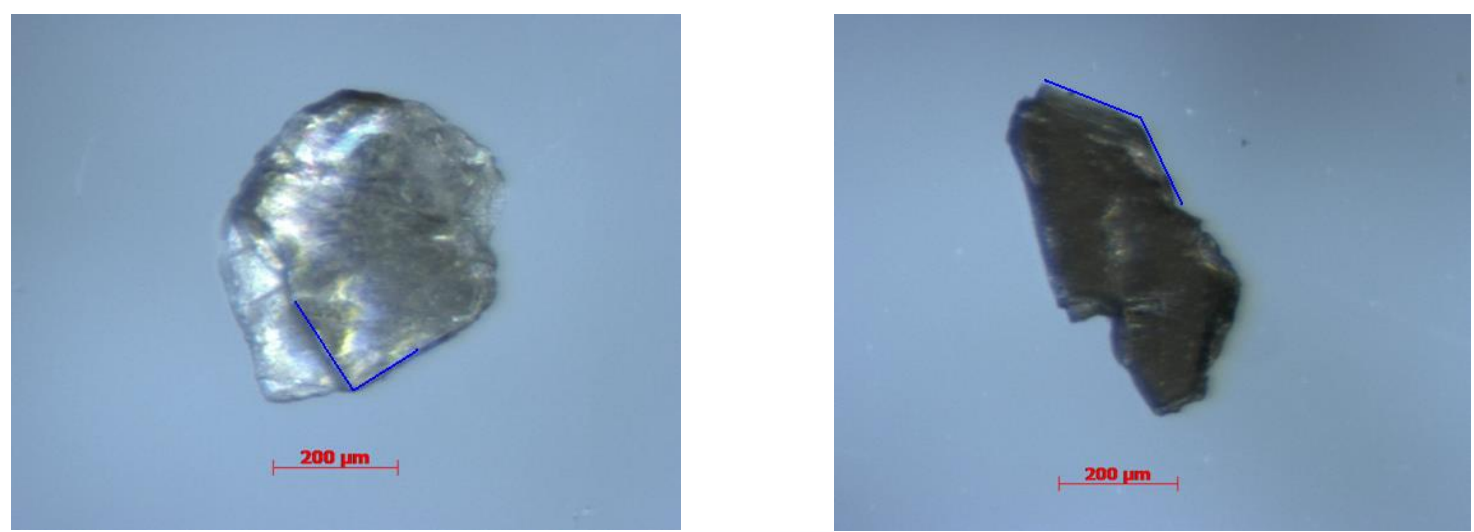

Figura 3. Partículas de flogopitito na faixa de tamanho entre 350 e 250 micrômetros mostrando sessões basais, com bordas demarcadas em azul, da mesma ordem de grandeza das partículas.

\subsection{Resultados do Ensaio de Moagem Herbst-Fuerstenau (H-F)}

Confirmando a tendência demonstrada no ensaio de Bond, o flogopitito mostra um comportamento de moagem sem ser de primeira ordem para $P 80$ menor que 300 micrômetros. Assim, o ensaio $H-F$ foi realizado objetivando um $P 80$ em torno de 300 $\mu \mathrm{m}$. Parâmetros de moagem do flogopitito para escalonamento de moinhos de bolas foram determinados utilizando-se a metodologia de Herbst-Fuerstenau. Os seguintes parâmetros do modelo de balanço populacional foram obtidos:

Tabela 3. Resultados do ensaio Herbst-Fuerstenau

\begin{tabular}{ccc}
\hline Parâmetro da funcão seleção & Seco & $\mathbf{7 0 \%}$ sólidos \\
\hline $\mathrm{S} 1, \mathrm{~min}^{-1}$ & 0,2189 & 0.4978 \\
\hline $\mathrm{S} 1 \mathrm{E}, \mathrm{t} / \mathrm{kWh}$ & 0,2189 & 0,4978 \\
\hline$\zeta 1$ & \multicolumn{2}{c}{0,6358} \\
\hline$\zeta 2$ & & -0.2889 \\
\hline Parâmetros da função quebra & \\
\hline$\gamma$ & & 0,8164 \\
\hline$\beta$ & & 7,5746 \\
\hline$\phi$ & & 0,6215 \\
\hline NSR & $\mathbf{0 , 9 5 8 6}$ & $\mathbf{1 , 2 8 3 3}$ \\
\hline
\end{tabular}

\footnotetext{
* Contribuição técnica ao $69^{\circ}$ Congresso Anual da ABM - Internacional e ao 14ํㅡㄹ ENEMET - Encontro Nacional de Estudantes de Engenharia Metalúrgica, de Materiais e de Minas, 21 a 25 de julho de 2014, São Paulo, SP, Brasil.
} 


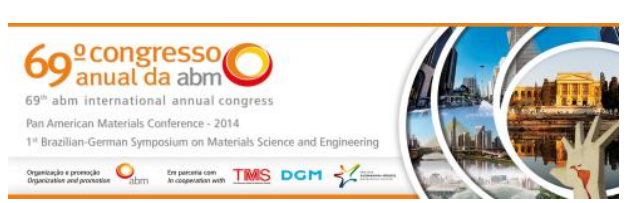

A moagem a úmido produz exatamente a taxa de moagem a seco, assim este tipo de rocha foge do comportamento usual que é uma maior taxa de moagem com a adição de água. A simulação com os parâmetros da Tabela 3 deve ser feita com o cuidado de manter o P80 acima de $228 \mu \mathrm{m}$ sob pena de produzir valores de energia muito abaixo do requerimento real.

\subsection{Resultados do Ensaio na Prensa de Rolos de Alta Pressão (HPGR)}

O flogopitito foi testado na prensa $\angle A B W A L$ utilizando-se a metodologia proposta por Schneider e Alves [3], em seis pressões iniciais de moagem. Os parâmetros obtidos para simulação são mostrados na Tabela 4.

Tabela 4. Parâmetros de balanço populacional do ensaio na prensa de rolos $L A B W A L$

\begin{tabular}{|c|c|c|}
\hline \multirow{5}{*}{$\begin{array}{c}\text { Parâmetros } \\
\text { de quebra } \\
\text { em leito }\end{array}$} & $\kappa @ 1 M P a s c a l, m m$ & 32,5 \\
\hline & $\alpha$ & 0,242 \\
\hline & $\gamma$ & 1,15 \\
\hline & $\beta$ & 1,16 \\
\hline & $\phi$ & 0,015 \\
\hline \multirow{5}{*}{$\begin{array}{l}\text { Parâmetros } \\
\text { de quebra } \\
\text { por contato } \\
\text { com os } \\
\text { rolos }\end{array}$} & $\mu, \mathrm{mm}$ & 8.947 \\
\hline & $\lambda$ & 1.205 \\
\hline & $\gamma$ & 0.803 \\
\hline & $\beta$ & 5 \\
\hline & $\phi$ & 0,99 \\
\hline \multicolumn{2}{|c|}{ A80, $\mathrm{mm}$} & 5,00 \\
\hline & N.S.R. & 9,96 \\
\hline
\end{tabular}

Os parâmetros da Tabela 4 foram obtidos com base nas condições operacionais de moagem e nas distribuições granulométricas resultantes, como mostradas na Figura 4.

É interessante observar que as distribuições da Figura 4 apresentam uma descontinuidade entre 200 e 300 micrômetros. Acima destes tamanhos as curvas demonstram uma tendência clara de geração de finos, porém, abaixo destes tamanhos, partículas finas não são produzidas nas proporções indicadas pela tendência. Isso indica que o tamanho da sessão basal da flogopita se encontra nesta faixa de tamanho, e o comportamento do flogopitito passa de friável para dúctil, não ocorrendo moagem significativa e/ou produção de finos abaixo de 300 micrômetros.

\footnotetext{
* Contribuição técnica ao $69^{\circ}$ Congresso Anual da ABM - Internacional e ao 14ํㅡㄹ ENEMET - Encontro Nacional de Estudantes de Engenharia Metalúrgica, de Materiais e de Minas, 21 a 25 de julho de 2014, São Paulo, SP, Brasil.
} 

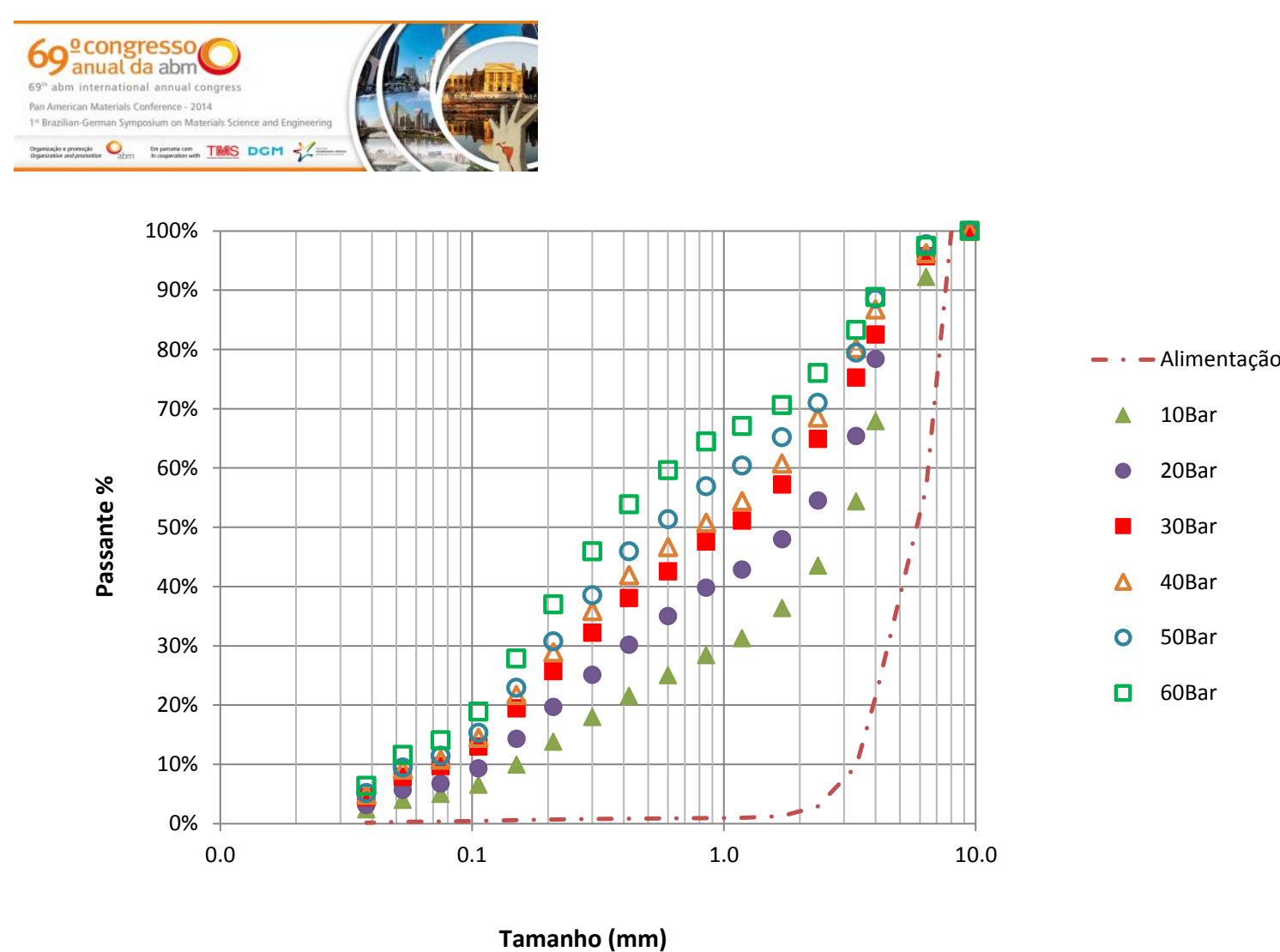

Figura 4. Resultados dos ensaios de moagem na prensa $L A B W A L$ com seis pressões iniciais de moagem distintas.

\section{CONCLUSÃo}

O flogopitito foi completamente caracterizado no que diz respeito às suas propriedades relativas às operações de britagem e moagem. Com os parâmetros obtidos, uma rota de processamento pode ser desenvolvida, incluindo britadores, moinhos e a prensa de rolos de alta pressão, e a demanda energética de processamento pode ser determinda de forma acurada par diversas configurações de planta. No entanto, o projeto de uma eventual planta de processamento deve levar em consideração que partículas finas, abaixo de 300 micrômetros, só podem ser produzidas em proporções pequenas, em função do comportamento dúctil da mica flogopita e do tamanho das sessões basais dos cristais individuais. Assim, projetos de cominuição devem ser especificados para valores de $P 80$ relativamente altos, acima de 300 micrômetros.

Nestas condições, é provável que prensas de rolos de alta pressão não produzam benefícios energéticos significativos, uma vez que, estes benefícios são caracterizados pela maior capacidade de geração de finos destes equipamentos, para materiais friáveis.

Ao realizar os ensaios de Bond, a descontinuidade em torno de 300 micrômetros, que marca a transição entre rocha (friável) e mineral (dúctil), no caso do flogopitito, foi prontamente detectada. $O$ ensaio de Bond simplesmente não converge para valores de P80 menores que 300 micrômetros, automaticamente limitando a moagem do flogopitito. Por outro lado, o ensaio de $H-F$ não detecta esta transição claramente, exceto em condições que o ensaio não produz partículas na especificação desejada, quando o $P 80$ requerido é menor do que 300 micrômetros. Portanto, o procedimento do ensaio $H-F$ deve sempre exigir que a especificação do produto seja atingida, de forma a validar os parâmetros obtidos.

No caso do ensaio de Bond, fica claro que o BWI deve ser determinado na malha de teste que produz o produto desejado, não existindo um $B W I$ padrão que possa ser utilizado para qualquer especificação de produto.

* Contribuição técnica ao 69 Congresso Anual da ABM - Internacional e ao 14ํㅡㄹ ENEMET - Encontro Nacional de Estudantes de Engenharia Metalúrgica, de Materiais e de Minas, 21 a 25 de julho de 2014, São Paulo, SP, Brasil. 


\section{Agradecimentos}

Os autores agradecem o CNPq pelo apoio financeiro proveniente do fundo CTMineral, projeto 550270/2011-6.

\section{REFERÊNCIAS}

1 Deer WA, Howie RA, Zussman J. An introduction to the Rock-Forming Minerals. $2^{\text {nd }}$ ed. Harlow: Longman; 1992.

2 Van Straaten P. In: Agrominerais para o Brasil. Eds. Francisco RC, Luz FAB, Castilhos ZC. Rio de Janeiro: CETEM/MCT; 2010.

3 Schneider CL, Alves VK, Austin LG. Modeling the contribution of specific grinding pressure for the calculation of HPGR product size distribution. Minerals Engineering. 2009.

4 Tavares LM, Silveira MACW. Comparison of measures of rock crushability. In: Fine Particle Technology and Characterization. Meftuni Yekeler; 2008.

5 Norman TE, Decker JD. Tumbling Mill Characteristics. SME Mineral Processing Handbook, vol. 1. Section 3C, Chapter 1. SME, Weiss, N.L Editor, 1985.

\section{BIBLIOGRAFIA}

1 Aguiar MRMP, Novaes AC, Guarino AWS. Remoção de metais pesados de efluentes industriais por aluminossilicatos. Química Nova. 2002;25(6B):1145-1154.

2 Bigham JM, Bhatti TM, Vuorinen A, Tuovinen OH. Dissolution and structural alteration of phlogopite mediated by proton attack and bacterial oxidation of ferrous iron. Hydrometallurgy. 2001;59:301-309.

3 Brasil TFM, Schneider CL. Caracterização da degradação de uma rocha utilizando o modelo de quebra por impacto. In: XXV Encontro Nacional de Tratamento de Minérios e Metalurgia Extrativa; 2013; Goiânia, Brasil. 2013.

4 Brindley GW, Brown G. Crystal Structure of Clay Minerals and their X-Ray Identification. London: Mineralogical Society; 1980.

5 Napier-Munn TJ, Morrell S, Morrison RD, Kojovic T. Mineral Comminution Circuits: Their Operation and Optimization. JKMRC Monograph Series in Mining and Mineral Processing, vol. 2. Brisbane: University of Queensland; 1996.

\footnotetext{
* Contribuição técnica ao $69^{\circ}$ Congresso Anual da ABM - Internacional e ao 14ํㅡㄹ ENEMET - Encontro Nacional de Estudantes de Engenharia Metalúrgica, de Materiais e de Minas, 21 a 25 de julho de 2014, São Paulo, SP, Brasil.
} 